Hautarzt 2012 $\cdot 63: 256-256$

DOI 10.1007/s00105-012-2328-9

(c) Springer-Verlag 2012

Am 25. Februar 2012 ist Professor Dr Hans Christian Korting an schwerer Krankheit verstorben. Wir trauern um ihn und werden ihn nicht vergessen.
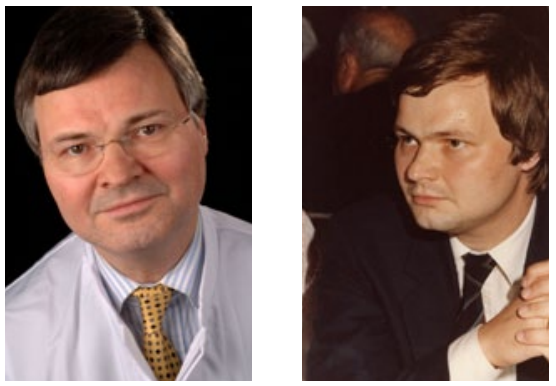

Lieber Hans,

wir alle gratulieren Dir ganz herzlich zu Deinem Geburtstag.

Dein Thomas

$$
\text { Thomes Rus la }
$$

Prof. Dr. Dr. h.c. Thomas Ruzicka mit den Mitarbeitern der Klinik und Poliklinik für Dermatologie und Allergologie der Ludwig-Maximilians-Universität München

\title{
Professor Dr. Hans C. Korting zum Geburtstag
}
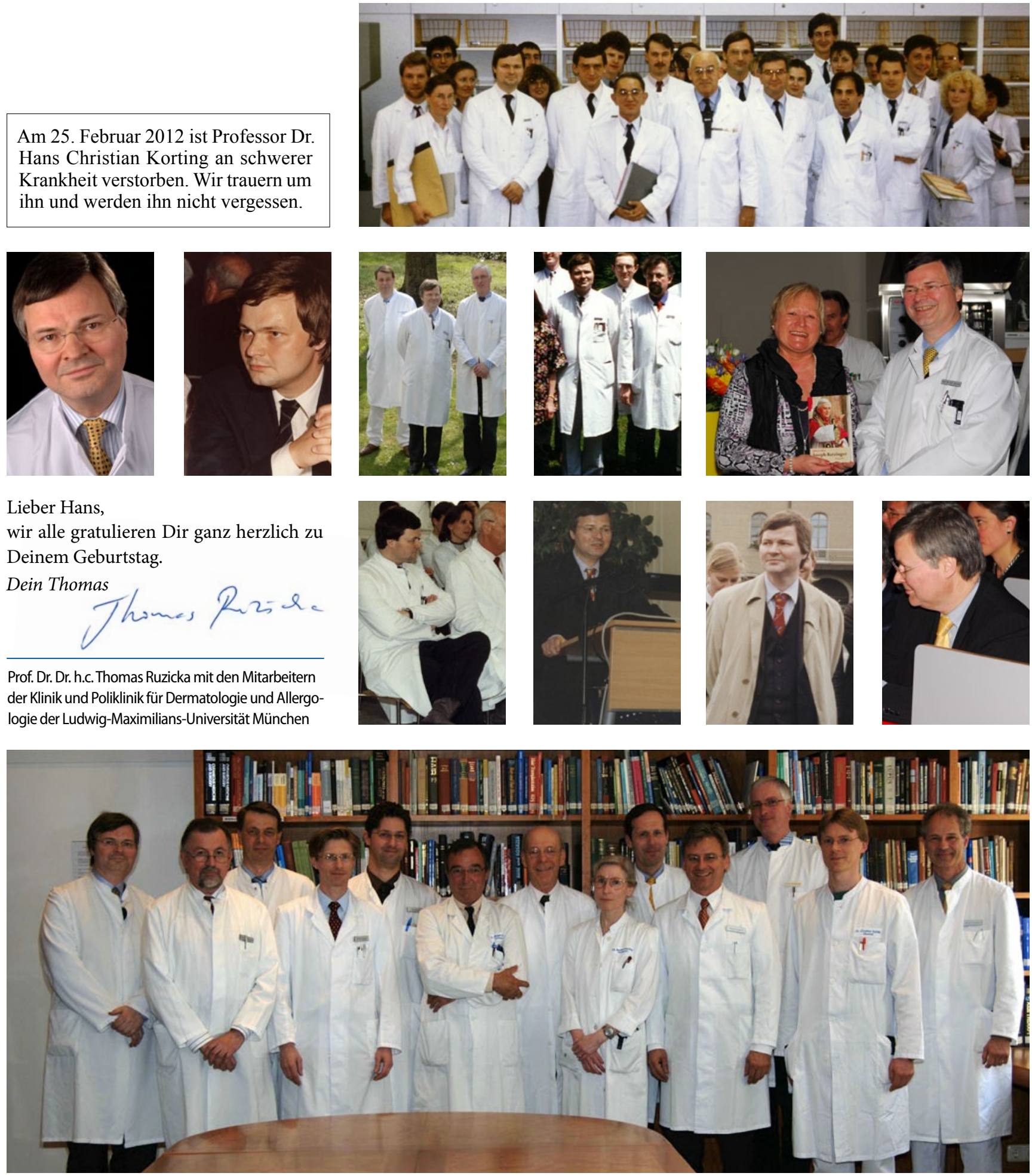

Fotos mit freundl. Genehmigung Frau G. Henning-Wrobel sowie Klinik und Poliklinik für Dermatologie und Allergologie, Ludwig-Maximilians-Universität München 